\title{
ATIVIDADE DE ESTUDO NO PRIMEIRO ANO DO ENSINO FUNDAMENTAL: IMPLICAÇÕES PEDAGÓGICAS NO INGRESSO DA CRIANÇA DE SEIS ANOS
}

\author{
Leonardo de Angelo Orlandi, José Milton de Lima
}

Universidade Estadual Paulista - UNESP, Programa de Pós-graduação em Educação, Presidente Prudente, SP. E-mail: leo_angeloorlandi@hotmail.com

\section{RESUMO}

Esta pesquisa partiu do pressuposto de que as atividades de estudo são uma importante fonte de humanização no contexto escolar e estabeleceu como objetivo central: acompanhar e interpretar as manifestações das crianças de seis anos acerca das atividades de estudo em uma turma de primeiro ano do Ensino Fundamental. O interesse em investigar tal tema adveio da constatação de que os descompassos decorrentes do ingresso das crianças de seis anos no primeiro ano do Ensino Fundamental geram diversos paradoxos propícios para reflexões na forma de conceber a educação para a infância. A investigação de natureza qualitativa adotou como metodologia a abordagem descritivo-interpretativa e, para tal fim, utilizou-se como procedimento metodológico a observação participante. Os resultados demonstram que o ingresso da criança de seis anos de idade, de maneira abrupta, gera alguns desconfortos e dificuldades de fruição das atividades de estudo, uma vez que as condições sociais desse local tornam-se diferentes daquelas vivenciadas outrora por elas na Educação Infantil. Por outro lado, os episódios apresentados nesta pesquisa demonstram que o estudo para as crianças pode auxiliar na compreensão do mundo e por este motivo torna-se uma atividade extremamente importante em sua vida. Por fim, a pesquisa aponta como necessidade a organização do processo educativo de tal forma que integre e respeite igualmente os aspectos da atividade lúdica e das atividades de estudo, atendendo as especificidades e os modos de agir das crianças.

Palavras-chave: Educação. Infância. Ensino Fundamental.

\section{STUDY OF ACTIVITY IN FIRST YEAR PRIMARY EDUCATION: EDUCATIONAL IMPLICATIONS IN ADMISSION THE CHILD OF SIX YEARS}

\begin{abstract}
This research assumed that the study activities are an important source of humanization in the school context and established as a central goal: to monitor and interpret the manifestations of children six years about the study activities in a class of first year of elementary school. The interest in investigating this subject came from the realization that the mismatches arising from the entry of six year olds in the first year of elementary school generate many paradoxes prone to reflections on how to design education for children. The qualitative research methodology adopted as a descriptive and interpretive approach and, for this purpose, was used as a methodological procedure participant observation. The results demonstrate that the entry of sixyear-old abruptly generates some discomforts and difficulties of enjoyment of study activities, since the social conditions that place become different from those experienced by them once in Early Childhood Education. On the other hand, the episodes presented in this study demonstrate that the study for children can help in understanding the world and for this reason it is an extremely important activity in your life. Finally, the research shows how necessary the organization of educational process in such a way that integrates and also respects the aspects of play activity and study activities, given the specificities and modes of action of children.
\end{abstract}

Keywords: Education. Childhood. Elementary School. 


\section{INTRODUÇÃO}

Instituições de educação para crianças, de modo geral, têm considerado a infância como um dado universal e categoria natural. Tal contexto educacional pouco favorece a experiência com o conhecimento científico, tampouco com a cultura, seja esta entendida em sua dimensão de produção nas relações sociais cotidianas, ou como produção historicamente acumulada, presente na literatura, na música, na dança, no teatro, na brincadeira, enfim, na produção artística e científica. No primeiro ano do Ensino Fundamental, o problema se acentua, principalmente pelo descompasso entre a redução do tempo de permanência da criança na Educação Infantil e a ampliação do tempo no Ensino Fundamental, no qual são gerados contextos artificiais que obrigam as crianças a se adaptar às situações pedagógicas até mesmo desprovidas de sentido para elas.

A partir da aprovação da Lei no 11.274 (BRASIL, 2006), o Ensino Fundamental passou a ter a duração de nove anos, com a inclusão obrigatória das crianças de seis anos nesse estágio da escolaridade. Nesse movimento abrupto, a implementação do ensino de nove anos e, consequentemente, a inserção de crianças com seis anos de idade nesta modalidade de ensino transformam-se em verdadeiro tormento para aquelas que são obrigadas a se adaptar às situações e aos conteúdos ora exigidos.
$\mathrm{Na}$ contramão das concepções adultocêntricas instaladas na educação brasileira, o Enfoque Histórico-Cultural concebe a criança como sujeito de sua atividade, capaz e competente na sua relação com o mundo (MELLO, 2007). Tal visão contribui para a formação de uma criança rica em possibilidades e capacidades, ativa e curiosa para se engajar no mundo da cultura, historicamente constituído. A infância, por sua vez, em lugar de ser entendida como um acontecimento estático, mergulhado em um vazio social, é vista como um fenômeno concreto e, por isso, mediatizado, num processo dialético, por temas sociais, culturais, políticos e econômicos do mundo contemporâneo.

Tomando por base essa forma de conceber a infância, com clareza da historicidade dessa concepção que compreende a criança como sujeito da sua atividade, é preciso investir em pesquisas que propiciem a interlocução com a realidade educacional, contribuindo para a compreensão crítica dos fatores limitadores da aprendizagem e da formação humana da criança, também para a produção de conhecimentos que subsidiem a construção de práticas educativas de valorização e de respeito à criança e à infância. Para tanto, a investigação contemplou as ações educacionais de estudo voltadas às crianças, pois entende que instituições do Ensino Fundamental e educadores do primeiro ano 
sentem dificuldades na utilização de conteúdos que valorizem as especificidades da criança de seis anos. A partir dessas considerações iniciais, o objetivo principal da pesquisa foi, portanto, o de acompanhar e interpretar as manifestações das crianças de seis anos acerca das atividades de estudo em uma turma de primeiro ano do Ensino Fundamental.

\section{METODOLOGIA}

A opção pelo objeto de estudo se concretizou por meio das discussões suscitadas nas reuniões do Grupo de Pesquisa da Faculdade de Ciências e Tecnologia UNESP, Campus de Presidente Prudente, denominado "Cultura Corporal: Saberes e Fazeres" e também pelos resultados de trinta meses de desenvolvimento de iniciação científica, nos quais constatamos um número reduzido de pesquisas destinadas ao estudo dos conteúdos destinados às crianças de seis anos e ainda lacunas existentes nas produções divulgadas.

Diante dessas definições, a investigação caracterizou-se como pesquisa de natureza qualitativa e adotou a metodologia do tipo descritivointerpretativa, considerando que a exposição das características do grupo pesquisado, do contexto e do fenômeno na sua relação com suas distintas variáveis, contribuiu para explicitar o problema da pesquisa e, ao mesmo tempo, permitiu analisar $\mathrm{e}$ compreender as manifestações das crianças na realidade vivenciada. A pesquisa de campo se desenvolveu em uma instituição da Rede Municipal de Educação de Presidente Prudente, tendo como universo um professor e 20 crianças do primeiro ano do Ensino Fundamental.

$\mathrm{Na}$ instituição de Ensino Fundamental selecionada são atendidas crianças de 6 anos incompletos à 10/11 anos, distribuídas em cinco anos através do critério de faixa etária. A formação da turma obedece o critério de faixa etária, devendo, portanto, ser composta por crianças de idade de 5 anos à completar 6 até 31 de março, conforme o Parecer CNE/CEB no 22/2009, de 09 de dezembro de 2009. Especificamente na classe investigada se encontravam três crianças com idade de 5 anos que completariam 6 após 31 de março. Existiam oficialmente 21 crianças matriculadas, no entanto, apenas 20 participaram do estudo pelo fato dos responsáveis não terem assinado o Termo de Consentimento Livre e Esclarecido.

Todos os participantes são residentes do mesmo bairro, oriundos de localizações diferentes. Em geral a professora conhece a família, irmãos mais velhos e mais novos, que frequentam ou não a instituição e, consequentemente, compartilha dos problemas da dinâmica familiar, através de contatos informais, ocorridos, geralmente, na própria escola. 
É importante ressaltar que a observação do agrupamento ocorreu no período de 26 de março a 03 de dezembro de 2012, totalizando 120 horas. O processo de observação foi realizado semanalmente e em dias alternados, para que fosse possível, desse modo, presenciar grande parte das atividades programadas na estrutura curricular. Vale destacar, ainda, que a identidade da instituição escolar, das crianças e da professora investigadas serão mantidas em sigilo, a fim de evitarmos qualquer tipo de perseguição ou exclusão por conta de suas opiniões, relatos e realidades.

Para garantir essa condição, no início das observações, após a aprovação do Comitê de Ética em Pesquisa e da assinatura do Termo de Consentimento Livre e Esclarecido, conversamos com as crianças a respeito da realização da pesquisa e perguntamos a elas se concordavam em participar do estudo. Todas as crianças responderam que sim e, desse modo, oferecemos à todas as crianças que escolhessem nomes fictícios para garantir que suas opiniões não gerassem constrangimentos após a pesquisa. Os nomes escolhidos foram:

- Meninas - Pequena Sereia; Cinderela; Pequena Polegar; Mulher Gata; Sininho; Globeleza; Shaiene; Magali; Minie; Rapunzel.
- Meninos - Ben Dez; Aladin; Robin Hood; Ali Babá; Pinóquio; Pequeno Polegar; Homem Aranha; Mickey; Patati; Patatá.

Já em relação a professora, a escolha foi feita aletoriamente, visto que nossa intenção maior no estudo era como a criança se manifesta nessa nova etapa em sua vida. Nesse sentido, participar das aulas junto com as crianças do primeiro ano possibilitou registrar o cotidiano educacional do grupo em questão, no qual se integram crianças de cinco e seis anos respectivamente, que poderiam indicar as mudanças e transições efetuadas na passagem da Educação Infantil para o Ensino Fundamental.

Ao longo da coleta de dados, procedemos à classificação dos episódios registrados por áreas de atividade ou objetos do conhecimento trabalhados. Elaboramos, portanto, uma descrição sumária dos registros, com enfoque mais particularizado nas manifestações das crianças em suas brincadeiras e atividades formais de ensino, o que possibilitou um mapeamento geral de todo o material coletado. As análises centraram-se em episódios experienciados pelas crianças que podiam ser agrupadas em função de sua configuração: relações sociais; importância e reconhecimento da atividade; tempo e espaço/rotina; conteúdos e propriedades. 
A partir dessa organização, foi possível um investimento no sentido de identificar a frequência com que os episódios ocorriam dentro da rotina escolar, e padrões de significação das crianças em relação as atividades, que pudessem ser organizados em categorias que refletissem o que havia de típico em suas vivências.

A logística estruturada nesse trabalho permitiu, portanto, o acolhimento de materiais consistentes, que orientou a formulação desta pesquisa que retrata as manifestações das crianças no primeiro ano do Ensino Fundamental.

\section{RESULTADOS}

No avanço para a aprendizagem escolar, ocorrem mudanças significativas em todas as esferas da vida da criança. Neste período, inicia-se o estudo como obrigatória, responsável, que exige um trabalho organizado e sistemático. Para Vigotski (2003), a transição da idade pré-escolar à idade escolar começa por uma etapa de crise ou viragem, descrita como a crise dos sete anos. Na visão do autor (2003), se trata de um período de grande mudança: a criança já não é um pré-escolar, nem tampouco um escolar. Portanto, para o autor (2003) tal passagem muda sensivelmente a criança e os recursos para o ensino se tornam mais complexos.

De acordo com Elkonin (1998), a atividade de estudo aparece no momento em que a criança está inserida em um sistema de ensino sistematizado. Portanto, para o autor (1998) não são mais as relações sociais (por meio das brincadeiras de faz de conta) que são determinantes para o desenvolvimento psíquico da criança, mas as características sistemáticas dos objetos sociais. Nesse período, a criança se depara com um contexto que exige atividades escolares mais sistematizadas, isto é, o estudo e os diferentes aspectos que o compõem, a organização escolar, como pontualidade, disciplina, responsabilidade e conteúdos diferentes do período pré-escolar.

Mukhina (1995, p. 297), por sua vez, reitera que o ingresso na escola representa uma virada na vida da criança, que transforma toda a sua existência, "situa-a numa nova posição social e lhe possiblita novas relações com os adultos e com seus coetâneos".

Para Bozhovich (2003) esta atividade estabelece na criança a tarefa de assimilação consequente, planejada, de conhecimentos generalizados e sistematizados dos fundamentos da ciência, o que pressupõe uma estrutura de sua atividade cognoscitiva completamente distinta da infância préescolar.

De acordo com a autora,

El ingreso em la escuela significa una nueva posición del niño en la sociedad, en el estado, lo que se expressa en la transformación de sus relaciones concretas com las 
personas que lo rodeam. Lo principal en este cambio consiste en un sistema totalmente nuevo de exigencias planteadas al niño y vinculadas con sus nuevas obligaciones, importantes no sólo para él mismo y para su família, sino tambiém para la sociedad. (BOZHOVICH, 2003, p. 09)

Nesse sentido, é consenso entre Vigotski (2003), Bozhovich (2003) e Davidov (2003a) que essa etapa é caracterizada pela perda da espontaneidade infantil. Segundo Vigotski (2003), a razão da espontaneidade infantil encontra-se na falta de diferenciação suficiente da vida interior e da exterior. Isso quer dizer que as vivências das crianças, seus desejos, suas manifestações não se diferenciam na sua execução e não apresentam caráter formal.

Por outro lado, nas atividades dos adultos, a diferença entre elas é constante e formal, portanto, o seu comportamento não é tão espontâneo e ingênuo como o da criança. Na visão do autor (2003, p. 60), quando a criança chega nesse período de transição da pré-escolar, "el espectador más candoroso se da cuenta inmediatamente de que el niño pierde pronto su ingenua espontaneidad, que en su conducta, en sus relaciones com lo demás, ya no resulta tan comprensible como antes".

Em relação a este excerto, analisemos a seguinte situação:

Ben Dez estava brincando de avião com a borracha quando a professora the chamou à atenção: Ben Dez pare de brincadeira, agora é hora de estudar, se não vou te levar para a diretora aí você vai ver. Ben Dez, por sua vez, deixou a borracha de lado pegou o seu lápis e abaixou a cabeça se voltando ao caderno. (DIÁRIO DE CAMPO, DIA 12/08/2012)

Através desse exemplo podemos perceber que as exigências escolares começam a ser determinantes do comportamento das crianças, visto que o espaço para brincar se faz em momentos parciais e segmentados. Em relação a essa questão Bozhovich (2003), aponta que em correspondência com a mudança de posição da criança e a aparição de uma nova atividade fundamental, a de estudo, se reestrutura todo o curso cotidiano da vida da criança.

El descuidado pasatiempo del
prescolar se transforma en
una vida plena de
preocupaciones
responsabilidad, debe asistir a
la escuela, estudar as
asignaturas determinadas por
el programa escolar, hacer en
la clase lo que piede el
maestro; debe seguir
estrictamente el régimen
escolar, someterse a las
regras de conducta de la
escuela, lograr una buena
asimilación de los
conocimientos y hábitos
señalados en el programa.
(ibidem, 2003, p. 10)

Nesse sentido, em relação a perda de espontaneidade infantil, Vigotski afirma que tal processo significa que a criança internaliza à sua conduta o fator intelectual que se 
insere entre a vivência e o ato direto, "lo que viene a ser el polo opuesto de la acción ingenua y directa del niño" (2003a, p. 61). Entretanto, isso não significa que a entrada da criança no Ensino Fundamental passa da vivência direta, ingênua, não diferenciada, ao extremo oposto; tal situação significa que em cada situação social nova, em cada vivência e em cada uma de suas manifestações aparece, consequentemente, um certo momento planificado e intelectual.

Assim, a qualidade do trabalho do escolar, assim como toda a sua conduta são valorizados pela escola, e esta apreciação influencia na atitude das pessoas que 0 circudam. Contudo, "el niño negligente en las obligaciones escolares, que no desea estudiar, es tratado com reprobación, [...] lo que introduce tensión en su vida, crea uma atmósfera de malestar y provoca ne él vivencias emocionales desagradables, que a veces resultan muy penosas" (BOZHOVICH, 2003, p. 10).

Tal situação pode ser visualizada no seguinte exemplo:

Patatá não estava querendo resolver os problemas que a professora estava propondo no quadro e conversava incessantemente com seu colega ao lado. Nesse momento, a professora interferiu e disse a Patatá que era preciso resolver os problemas propostos. Após alguns momentos a professora volta e vê que Patatá não estava realizando as tarefas. Vendo que não estava realizando, a professora começou a tratar Patatá de maneira ríspida e esse tratamento começou a gerar um mal estar em Patatá que afirmou posteriormente que estava cansado de tanto estudar e queria ficar mais sossegado. (DIÁRIO DE CAMPO, DIA - 20/08/2012)

Essa situação confirma as ideias de Mukhina (1995), que destaca que na situação do escolar seus estudos são uma atividade obrigatória e tomada como socialmente importante. Para a autora (1995), nessa situação a criança precisa responder ante o professor, ante a escola e ante sua família pelo cumprimento das atividades propostas ou mesmo impostas. Nesse sentido,

Entre o aluno e o professor estabelece-se um tipo de relação totalmente novo. O professor não é simplesmente um adulto que goza ou não da simpatia da criança, mas o portador real de certas exigências sociais para com a criança. A qualificação que a criança recebe na classe não reflete a atitude pessoal do professor frente à criança, mas é a medida objetiva de seus conhecimentos, de como cumpre seu dever de estudar (MUKHINA, 1995, p. 297).

Dessa forma, ao converter-se em escolar, a criança começa a empenhar/ocupar um novo lugar na sociedade, distinto daquele que ocupava enquanto pré-escolar. Recebe as obrigações que a sociedade the impõe e assume em sua atividade escolar uma responsabilidade mais séria do que aquela desempenhada antigamente. No entanto, segundo Bozhovich 
(2003, p. 10), conjuntamente com os novos deveres desta posição social, o escolar recebe novos direitos: "puede aspirar a una actitud seria por parte de los mayores hacia su tara docente; tiene derecho a un lugar de trabajo, al tiempo necesario para sus estudios, al silencio, al descanso, al tiempo libre".

Outro ponto positivo na inserção da criança ao estudo planificado e sistemático, é a participação conjunta em uma atividade obrigatória que oferece a possibilidade de novos tipos de relações recíprocas, baseadas na responsabilidade comum.

Resumindo as principais características das mudanças que ocorrem na vida da criança ao ingressar no Ensino Fundamental, podemos apontar enquanto mudança significativa o lugar do escolar no sistema de relações sociais. Para Bozhovich (2003, p. 10)

Aquí debe destacarse que la posición del escolar, debido a enseñanza general obligatoria y al sentido ideológico que en nuestra sociedad se concede al trabajo, incluyendo el docente, crea una tendencia moral especial de la personalidad del ñino. El estudio no es para él sencillamente una actividad de asimilación de los conocimientos ni un medio de prepararse para el futuro, sino que el niño lo comprende y lo siente también como su propia obligación de trabajar, como su participación en la vida laboral cotidiana de todos.
Estas condições acentuam a importância da escola como o centro da vida das crianças, visto que essa instituição carrega os interesses do escolar, propiciando interrelações e vivências significativas para seus ingressantes. Nesse processo, de acordo com Mukhina (1995) e Davidov (2003b) a vida psíquica interna da criança que se converte em escolar, recebe conteúdo e caráter totalmente distinto do que aquele outrora recebido na idade pré-escolar. “La forma en que habrá de cumplir com sus obligaciones escolares, si tiene éxito o no en sus estudios, tiene para él un profundo matriz afectivo" (BOZHOVICH, 2003, p. 11).

Em relação as questões afetivas geradas pela mudança de situação social das crianças na escola, Vigotski (2003) excerta que se generalizam pela primeira vez as vivências e os afetos.

Nesse momento, aparece a lógica dos sentimentos. Para o autor (2003)

El niño de edad escolar generaliza los sentimientos, es decir, cuando una situación se há repetido muchas veces nace uma realción afectiva que tiene la misma relación com la vivencia aislada o el afecto que el concepto con la percepción aislada o el recuerdo. Por ejemplo, el niño prescolar carece de autovaloración, de amor próprio. Justamente en la crise de los siete años es cuando surge la propia valoración: el niño juzga sus éxitos, su propia posición. (ibidem, 2003, p. 64) 
Assim, a nova situação social do desenvolvimento da criança possibilita maior estabilidade da esfera motivacional, isto é, "da jerarquía de motivos, lo cual se expresa en la voluntariedad de la conducta del escolar". (DOMíNGUEZ, 2003, p. 120).

Nesse processo, a criança escolar é capaz de orientar seu comportamento não somente por objetivos que determinam os adultos, mas também por comportamentos propostos conscientemente, alcançando um controle mais ativo de sua conduta. Esta voluntariedade da criança, segundo Domínguez (2003) se expressa pelos processos cognitivos, confirmando que a unidade do cognitivo e o afetivo alcança um maior nível e se converte na base da consolidação das formações motivacionais complexas (ideais e autovalorização) que caracterizam a personalidade em etapas posteriores do desenvolvimento.

Nesse sentido, aparecem na criança, que ingressa em um local em que as exigências sociais são extremamente diferentes daquelas vivenciadas anteriormente, diversas e complexas formações que modificam brusca e radicalmente o seu comportamento, embora essas dificuldades se diferenciem por princípio das existentes na idade pré-escolar (VIGOTSKI, 2003). Assim, no decurso do desenvolvimento as novas formações como os ideais, a autovalorização e o amor próprio se conservam, enquanto os sintomas das crises são transitórios.

Analisemos o exemplo de Globeleza durante a realização de uma atividade de ensino proposta pela professora:

Após várias tentativas
frustadas de resolução de um
exercício proposto pela
professora, Globeleza possuía
um semblante triste e
desmotivado. Tal situação
perdurou até o momento do
intervalo deixando a menina
desinteressada pela atividade.
No entanto, após o retorno do
intervalo, com ajuda da
professora, Globeleza
conseguiu resolver a situação
proposta pela professora. A
resolução do problema gerou
na menina felicidade e seu
semblante demonstrava um
certo ar de confiança. Dizia a
seus companheiros: “Viu
como eu fiz, agora eu sei”.
(DIÁRIO DE CAMPO, DIA -
13/09/2012)

Como podemos perceber, diante dessas transformações e exigências sociais que a criança vivencia na escola surgem alguns casos típicos de dificuldades educativas que não acontecem na etapa de ensino anterior. Vigotski (2003) nomea essas principais dificuldades como: conflitos; as vivências opostas e; as contradições insolúveis.

De hecho, cuando se produce tal desdoblamiento interno de vivencias, cuando el niño las comprende por primera vez, cuando se forma la relación interna es cuando se modifican las vivencias; sin esa modificación no sería posible la edad escolar. Decir que en la crisis de los siete años las vivencias prescolares 
se transforman tan sólo en escolares, equivale a decir que se ha formado uma nueva unidad de elementos situacionales y personales que hacen posible una nueva etapa del desarrollo, es decir, la edad escolar. Si decimos que la relación del niño con el medio ambiente se há modificado, significa que el próprio medio ya es distinto y que, por tanto, há cambiado el curso del desarrollo del niño, que há llegado a una nueva etapa del desarrollo. (VIGOTSKI, 2003, p. 65)

Outro ponto a ser ressaltado em relação ao meio social da criança é a importância que essa instituição tem na vida da criança, visto que a perda de posição que Ihe corresponde na escola ou a incapacidade de estar a sua altura, provocam na criança um sentimento de perda do centro de sua vida, daquele local de onde se sente membro de um todo social. Em relação a esse ponto, durante uma das conversas com as crianças perguntei a Lia porque ela gostava de ir a escola e o que ela mais gostava de fazer.

No episódio abaixo, encontraremos a importância que esta instituição tem para a menina e o que ela faria se a escola não existisse:

Pesquisador - Mulher gato, o que você faria se a escola não existisse.

Mulher Gato - Ah, não sei direito (abaixando a cabeça com vergonha).

Pesquisador - Como assim, não sabe? (risos) Porque você vem na escola?

Mulher Gato - Porque eu gosto.

Pesquisador - Do que você mais gosta na escola?
Mulher Gato - Das minhas amigas "ué".

Pesquisador - Só das amigas?

Mulher Gato - É, gosto também da professora, e mais ou menos das lições.

Pesquisador - Nossa você gosta de muita coisa, mas da lição não gosta muito né?

Mulher Gato - Mais ou menos (balançando as mãos), antes tinha menos lições agora tem mais.

Pesquisador - E se não existisse escola o que você iria fazer?

Mulher Gato - O que? Ai, ai, ai (rindo) é impossível.

Pesquisador - É se não existisse.

Mulher Gato - Não sei não só sei que eu iria ficar triste.

Pesquisador-Porque?

Mulher Gato - Porque eu venho aqui todos os dias.

E a conversa se estendeu por outros caminhos [...].

Por conseguinte, os problemas da aprendizagem escolar não são só questões da formação e do desenvolvimento intelectual da criança, mas também compreende aspectos da formação de sua personalidade em contato com o ambiente social. Durante muito tempo a psicologia só considerou como índice fundamental de preparação da criança para o ensino escolar o nível de seu desenvolvimento intelectual, mais exatamente, a bagagem de conhecimentos e ideias com que chega à escola. Precisamente, a ampliação do círculo de representações, e da intensidade de riqueza intelectual da criança era considerado uma garantia para sua aprendizagem na escola e para seus êxitos na aquisição de conhecimentos. 
Esta ideia produzida no fim do século XIX e princípios do XX geraram numerosas investigações dirigidas a bagagem intelectual quantitativa das crianças que ingressam na escola e ao estabelecimento das exigências que neste aspecto devem ser alcançadas pela criança.

Para Vigotski (2003), o efeito dessa ideia descaracterizou os estudos da relação interna da criança com as pessoas de seu entorno, desconsiderando-a como um participante ativo da situação social. Não obstante, tais investigações psicológicas e pedagógicas e a prática do ensino escolar, demonstram que não existe uma correspondência direta entre a bagagem de ideias e o nível geral do desenvolvimento mental da criança que garanta sua preparação intelectual para a aprendizagem escolar.

No entanto, Vigotski (2003) foi um dos primeiros, a formular claramente 0 conceito de que a preparação para a aprendizagem escolar, na dimensão do desenvolvimento intelectual da criança, consiste não exatamente na bagagem quantitativa de ideias, mas no nível de desenvolvimento dos processos intelectuais, isto é, nas particularidades qualitativas do pensamento infantil.

Partindo deste ponto de vista, estar preparado para a escola significa ter alcançado um determinado nível de desenvolvimento dos processos do pensamento: a criança deve saber distinguir o essencial nos fenômenos da realidade circundante, saber compará-los, ver as semelhanças e diferenças; deve aprender a raciocinar, a encontrar as causas dos fenômenos, a chegar a conclusões. De acordo com Mukhina (1995) e Bozhovich (2003), a criança que não é capaz de seguir um raciocínio do professor e conjuntamente com ele chegar a conclusões simples, não está preparada para o aprendizado na escola.

A esse respeito tomemos como exemplo o seguinte episódio:

Após a hora do conto, a
professora começou a montar
o cabeçalho na lousa com as
informações do dia. Iniciou-se
com o nome da escola,
posteriomente com o nome
dos ajudantes e a condição
climática do dia. Logo depois,
começou a contagem de
quantos alunos estavam
presentes na aula.
Professora - Vamos contar
quantas crianças estão
presentes hoje?
Professora - Vamos lá! 1, 2, 3,
4... continuou até o número
18.
Professora - Agora nós iremos
representar este número por
corações.

Nesse momento a professora desenha 18 corações na lousa, e pede para que Sininho conte os corações e confirme se realmente está certo a quantidade de corações. Ali babá, por sua vez, faz um comentário:

Ali babá - Ah Professora! coração é de menina! Professora - Não Ali Babá, todos nós temos coração. Coloca a mão do lado esquerdo pra você ver. 
Meninos e meninas tem coração! (com um tom um pouco mais acentuado).

Nesse momento, Aladin entra na conversa e expressa a seguinte opinião:

Aladin - É todos nós temos coração! Ele é invisível.

Ali Babá - É verdade ele fica invisível e o meu está batendo coloca a mão aqui pra você ver (virando para o lado de Aladin).

Sininho - Ai nada ver. O coração não é invisível ele fica dentro do corpo e bate o tempo todo.

Ali babá - Mas mesmo assim, o coração fica invisível.

Narizinho - Ele não é invisível não! Ele tem o formato que a professora desenhou na lousa e fica dentro do nosso corpo.

Nesse instante a professora intervém e pede para que as crianças prestem atenção na contagem dos números $\mathrm{e}$ assim a conversa se encerra. (DIÁRIO DE CAMPO, DIA 14/08/2012)

Como podemos visualizar no exemplo supracitado, as crianças observadas demonstraram certa dificuldade em explanar sobre o órgão: coração. Apesar de parecer óbvio que o coração é um orgão vital do corpo humano, para as crianças nesta idade, este tipo de conceito ainda é muito complexo. Entretanto, é possível encontrar nas suas falas alguns indícios do entendimento desse conceito, como por exemplo na fala de Sininho.

A fala dessa criança deixa evidente apesar de existir dificuldade para expressar o que seja o coração - as atitudes de pensamento planificado. Primeiro, ela rejeita a hipótese de ser invisível; posteriormente, afirma que ele fica dentro do corpo; e terceiro ela explana que esse orgão bate o tempo todo, isto é, uma condição vital do ser humano. Nessa dimensão, é perceptível que não são todas as crianças que já conseguem realizar uma diferenciação e generalização das questões por elas vivenciadas, no entanto, seus pensamentos caminham na direção do pensamento planificado e sistemático.

Nessa perspectiva, Vigotski (2003) infere que estar preparado para a escola significa, antes de tudo, saber generalizar e diferenciar as diferentes categorias dos objetos e fenômenos do mundo circundante. Para Bozhovich (2003), a internalização de qualquer conteúdo evidencia a presença na criança da capacidade de distinguir e de fazer objeto de sua consciência aqueles fenômenos da realidade cujo conhecimento deve assimilar. Tal processo determina o nível de generalização.

Normalmente, as crianças de idade pré-escolar não possuem tal nível de desenvolvimento do pensamento. Por exemplo, eles não sabem diferenciar a natureza física daquilo que é elaborado pelo homem, pelo social e pelo natural.

Leontiev (2006b) afirma que apesar de a criança nessa idade ainda não saber diferenciar alguns conceitos é preciso paulatinamente inserir no decurso do seu 
cotidiano o ensino planificado e sistemático antes mesmo de seu ingresso na idade escolar. No entanto, tal proposição não significa que os conteúdos do ensino fundamental sejam inseridos na educação infantil, mas é preciso que a etapa anterior ao ensino fundamental colabore na preparação da criança inserido conteúdos que ajudem a criança a planificar e sistematizar de maneira mais geral os conteúdos.

A respeito da pertinência da atividade de estudo no trabalho pedagógico junto as crianças de seis anos Davidov (1988), que analisou o contexto de antecipação da escolarização aos seis anos de idade pela Reforma Escolar em 1984 na Rússia, não deixa dúvidas quanto a possibilidade de introduzir esse tipo de atividade na educação de crianças dessa faixa etária. Entretanto, para o autor (1988)

la organización de la actividad de los niños estudio seis años requiere el desarrollo y la introducción de nuevas formas y medios para llevarla a cabo. Además, en opinar que esta actividad, de una manera $u$ otra, debe comenzar a formar en los niños la base inicial de la conciencia y pensamiento teórico. (DAVIDOV, 1988, p. 83)

A suposição de Davidov (2003a) acerca da relação interna entre a atividade de estudo e os conhecimentos teóricos tem dois fundamentos: o primeiro está relacionado aos resultados da análise da história da instrução massiva e; o segundo está ligado com o exame das peculiariedades com que se apresenta o conteúdo das formas superiores da consciência social como objeto de assimilação por parte do indivíduo. Para Davidov (2003a) é de suma importância para a compreensão dos conteúdos e da estrutura da atividade de estudo o entendimento desses fundamentos. Assim, é determinante que examinemos esta fundamentação analisando o processo de assimilação dos conhecimentos científicos.

De acordo com Mammardashvili (1968, p. 21) com as ideias filosóficas modernas, o homem que assimila os conhecimentos científicos já não trata com a realidade imediatamente circundante, visto que o

$$
\begin{aligned}
& \text { objeto del conocimiento } \\
& \text { está mediatizado por la } \\
& \text { ciencia como formación } \\
& \text { social, por su historia y por } \\
& \text { la experiencia [...] en esse } \\
& \text { objeto se han separado } \\
& \text { determinados aspectos, } \\
& \text { dados al individuo que } \\
& \text { ingresa en la ciencia, en } \\
& \text { forma de contenido } \\
& \text { generalizado, abstracto, } \\
& \text { de su pensamiento. (apud } \\
& \text { DAVIDOV, 2003a, p. 211) }
\end{aligned}
$$

Ante ao exposto, Davidov (2003a) sublinha que a atividade de estudo dos escolares se estrutura em correspondência com o procedimento de exposição dos conhecimentos científicos e com o 
procedimento de promoção do abstrato ao concreto.

Na visão do autor,

El pensamiento de los alumnos, en el proceso de la actividad de estudio, tiene algo en comúm con el pensamiento de los científicos, quienes exponen los resultados de sus investigaciones por medio de las abstracciones $y$ generalizaciones sustanciales y los conceitos teóricos que funcionan en el proceso de ascensión de lo abstacto a lo concreto. (2003a, p. 212)

Entretanto, apesar de existirem alguns traços comuns no pensamento das crianças que elaboram procedimentos de abstração e generalização com o pensamento dos cientistas, artistas e teóricos, tais pensamentos não são idênticos. Davidov (2003a) aponta que os escolares realizam procedimentos equivalentes e adequados ao meio dos quais se elaboraram historicamente os produtos da cultura. "En su actividad de estudio los escolares reproducen el proceso real por el cual los hombres crean los conceptos, imágenes, valores y normas" (DAVIDOV, 2003a, p. 213). Por isso, o ensino escolar que se sustenta na tese que o homem só se desenvolve pelos processos de aquisição da cultura humana por intermédio da educação deve estruturar-se de maneira que em forma abreviada reproduza o processo real de geração e desenvolvimento dos conhecimentos.
Essas suposições para o pensamento do ensino para a criança de seis anos, na visão de Davidov (2003a) são imprescíndiveis, visto que

En la actividad de estudio las jóvenes generaciones reproducen en su conciencia las riquezas teóricas que la humanidad acumuló y expresó en las formas ideales de la cultura espiritual. Como otros tipos de actividad reproductiva de los niños, la de estudio conforma uma de las vías de realização de la unidad de lo histórico y lo lógico en el desarrollo de la cultura humana. (ibidem, 2003a, p. 213)

Davidov (2003a) ratifica que as crianças, ao iniciar a assimilação de qualquer disciplina científica, com a ajuda do professor, analisam o conteúdo do material, identificam algumas relações gerais iniciais, descobrindo simultaneamente que os fenômenos se manifestam em muitas outras relações particulares existente no material estudado. Conforme os alunos fixam, por intermédio dos signos, a relação geral inicial separada, as crianças constrõem a abstração substancial do objeto estudado.

De acordo com o autor (2003a), na continuação da análise de tal material os alunos descobrem uma certa vinculação regular da relação inicial com suas diferentes manifestações e, assim, apropriam a generalização substancial do objeto estudado. 
Nesse sentido, o autor (2003a) expõe

que as

[...] niños utilizam abstracción

y la generalización sustanciales para la deducción sucesiva (también con ayuda del maestro) de otras abstracciones más particulares y para su unión en el objeto integral (concreto) estudiado. Cuando los escolares comienzan a utilizar la abstracción y generalización iniciales como medios para deducir y unir otras abstracciones, ellos convierten las estructuras mentales iniciales en concepto, que fija cierta 'célula' del objeto estudiado. Esta 'célula' sirve posteriormente a los escolares como principio general para orientarse en toda la diversidad del material fáctico, que deben asimilar en forma conceptual por vía de la ascensión de lo abstracto a lo concreto. (2003, p. 214)

Dessa maneira, embora as atividades formais de ensino realizadas pelas crianças pequenas demonstrem estar em correspondência com o procedimento de exposição dos conteúdos da cultura humana elaborada historicamente, dentro destas atividades se mantém de forma peculiar, as situações e as ações que eram inerentes ao processo de criação real de tais produtos, devido ao procedimento de sua obtenção se reproduzir abreviadamente na consciência individual dos escolares. Assim, durante o cumprimento sistemático das atividades formais de ensino, desenvolvem-se nos alunos, junto com a assimilação dos conhecimentos teóricos, a consciência e o pensamento teórico. Em consonância com esta ideia, Davidov (2003a, p. 215) sintetiza que

En la edad escolar inicial la actividad de estudio es rectora y principal entre los otros tipos de actividad realizada por los niños. En el curso de la formación de la actividad de estudio, en los escolares de menor edad se constituye y desarrolla uma importante neoestructura psicológica: las bases de la conciencia y el pensamiento teóricos y las capacidades psíquicas a ellos vinculados (reflexión, análisis, planificación).

Dessa forma, iniciado desde Vigotski (2003), o centro de gravidade do entendimento da preparação intelectual da criança para o ensino escolar foi transposto da bagagem de ideias aos modos do pensamento infantil e ao nível de concientização e generalização de sua percepção da realidade. No entanto, as investigações (Davidov, 1988; Davidov, 2003a; Davidov, 2003b; Vigotski, 2003; Bozhovich, 2003) demonstram que o problema da distinção da tarefa de estudo e sua transformação no objeto independente da atividade do aluno, exige da criança que ingressa na escola um nível determinado do desenvolvimento de seus interesses cognoscitivos.

No bojo dessa discussão, quando se examina o processo de formação nos escolares de menor idade, da atividade de estudo, aparecem determinadas questões 
que merecem e requerem reflexões: a especificidade dos componentes estruturais (necessidades, motivos, tarefas, ações e operações) da atividade de estudo; as suas interrelações com outros tipos de atividades; a transição da brincadeira de papéis sociais para tal atividade; as etapas de seu desenvolvimento no curso da infância escolar.

\section{CONCLUSÕES}

Ao encerrarmos esta pesquisa sobre as manifestações das crianças de seis anos que ingressam no primeiro ano do Ensino Fundamental, sob o prisma do Enfoque Histórico-Cultural, entendemos, com base na apreensão do conjunto da exposição realizada até aqui, que podemos tecer várias análises e inferências sobre a implementação da proposta de expansão desse nível de ensino e suas implicações na vida da criança.

O material teórico e as análises das manifestações das crianças produzidos sobre a atividades de estudo, tecido segundo os pressupostos e as opções metodológicas do enfoque histórico-cultural, oferecem indicadores suficientes sobre a natureza social da origem dessas esferas de ação humana, tanto do ponto de vista filogenético, quanto do ponto de vista ontogenético. Tal concepção disponibiliza análises substanciais sobre o desenvolvimento das diferentes manifestações da crianças no estudo, atravessado por alterações e incrementos em outras dimensões de desenvolvimento infantil, em especial a linguagem, a imaginação, a regra e indubitavelmente as relações com o outro, que precisam estar presentes em toda a trajetória de formação humana do sujeito.

A pesquisa se empenhou, portanto, com a busca de condições sociais concretas, que interferem e modulam as transformações dos processos psíquicos e atividades humanas. Nesse contexto, a mudança da condição social da criança de seis anos que antes pertencia ao universo da Educação Infantil tornou-se um importante tema de investigação para a compreensão da inserção da criança no Ensino Fundamental no sexto ano de vida.

Ao procurar entender as manifestações das crianças em relação ao estudo, compreendemos que para as crianças o ingresso em um espaço com mais exigências gera alguns desconfortos e dificuldades de fruição das atividades de estudo, uma vez que as condições sociais desse local tornam-se diferentes daquele vivenciado outrora por elas na educação infantil. Por outro lado, os episódios apresentados nesta pesquisa demonstram que o estudo, para as crianças, tem como objetivo auxiliar na compreensão do mundo e por este motivo torna-se uma atividade necessária e importante em sua vida.

Nessa direção, o professor do primeiro ano precisa organizar o processo 
educativo de forma integrada, respeitando igualmente os aspectos da atividade lúdica e das atividades de estudo, atendendo as especificidades e os modos de agir das crianças. Consideramos que organizar o ensino de forma que inicialmente essas atividades estejam entrelaçadas, enriquecendo-se mutuamente, significa conduzir racionalmente 0 processo de transição. Tal organização pode evitar a crise que tende a ser gerada pela repentina ruptura da atividade lúdica, apenas porque a criança legalmente passou a frequentar o ensino obrigatório. Todavia é essencial que, nesse processo, o professor saiba, aos poucos, transmitir aos alunos maior valor ao prazer de conhecer do que somente o prazer do brincar, levando a criança a perceber a riqueza do novo lugar que ela passa a ocupar como estudante do Ensino Fundamental. Dessa forma, a atividade lúdica estaria oferecendo aportes para o surgimento da nova atividade.

Por fim, a inclusão da criança no primeiro ano do Ensino Fundamental de nove anos não se constitui algo negativo, mas uma oportunidade de inserir atividades promotoras do seu desenvolvimento.

\section{REFERÊNCIAS}

BORONAT, M. E. Formación de las premisas del juego de roles em el tercer año de vida. In: GOMÉZ, A. M. S. et al. Estudio sobre las particularidade del dessarrolo del niño preescolar cubano. La Habana, Pueblo y Educación, 2002.

BOZHOVICH, L. El problema de la preparación del niño pra el aprendizaje escolar. In: IZNAGA, A. L. S.; CAMPO, G. A. M.; PÉREZ, M. E. R. Psicología del desarrolo del escolar: selección de lecturas. La Habana, Félix Varela, 2003.

Lei no. 11.274/2006. Altera a

redação dos artigos 29, 30, 32 e 87 da Lei no. 9.394, de 20 de dezembro de 1996. Diário Oficial [da] República Federativa do Brasil, Brasília, DF, 2006. Disponível em:

<http://www.planalto.gov.br>. Acesso em: 05 ago. 2010.

DAVIDOV, V. Problemas del desarrollo psíquico de los niños. In. ___ La enseñanza escolar el desarrollo psiquico. Moscú: Editorial Progresso, 1988.

DAVIDOV, V. Contenido y estructura de la actividad de estudio. In: IZNAGA, A. L. S.; CAMPO, G. A. M.; PÉREZ, M. E. R. Psicología del desarrolo del escolar: selección de lecturas. La Habana, Félix Varela, 2003a.

DAVIDOV, V. El estudio como actividad en el escolar pequeño. In: IZNAGA, A. L. S.; CAMPO, G. A. M.; PÉREZ, M. E. R. Psicología del desarrolo del escolar: selección de lecturas. La Habana, Félix Varela, 2003b.

DOMÍNGUEZ, L. Edad escolar. In: IZNAGA, A. L. S.; CAMPO, G. A. M.; PÉREZ, M. E. R. Psicología del desarrolo del escolar: selección de lecturas. La Habana, Félix Varela, 2003.

ELKONIN, D. B. Psicologia do jogo. São Paulo: Martins Fontes, 1998.

MELLO, S. A. Infância e humanização: algumas considerações na perspectiva histórico-cultural. Perspectiva, Florianópolis, v. 25, n. 1, 83-104, jan./jun. 2007. 
MUKHINA, V. Psicologia da idade pré-

escolar. São Paulo: Martins Fontes, 1995, 324

p.

VIGOTSKY, L. S. La crisis de los siete años. In:

IZNAGA, A. L. S.; CAMPO, G. A. M.; PÉREZ, M.

E. R. Psicología del desarrolo del escolar:

selección de lecturas. La Habana, Félix Varela, 2003.

Recebido para publicação em 17/08/2015

Revisado em 01/09/2015

Aceito em 10/09/2015 